\title{
An Exploratory Study of Omni-Channel Retailing Strategies in the Drugstore Industry: The Case of B Company in Taiwan
}

\author{
Wei-Jen Huang \\ Department of Business Administration \\ National Chengchi University \\ E-mail: 103355506@nccu.edu.tw
}

Taiwan

\section{ABSTRACT}

In recent years, 020 was becoming an important channel strategy actively explored by major companies. This new $\mathrm{O} 20$ model was an important marketing development trend, especially within the retail industry. The drugstore industry in Taiwan should also consider using this strategy. However, Philip Kotler emphasized in Marketing 4.0 that the mobile and community era was at hand, represented by the concept of "Mobile Community Marketing," which could be interpreted as bringing businesses and consumers together to connect virtual and physical networks.

The current study utilized a case method and selected B company as the research object. Several in-depth interviews with multiple senior management directors were conducted. The study findings indicated that omni-channel retailing strategies were becoming more popular and the case company will continue to implement this kind of retailing strategy. The results of this paper could generalize some practical marketing suggestions for the drugstore industry.

\section{KEYWORDS: drugstores; O2O; omni-channel retailing strategies; omni-channel marketing}

\section{Introduction}

With the continuous advancement of Internet technology and the rapid rise of e-commerce, Taiwanese chain drugstores use the Internet to execute various marketing strategies. Furthermore, the traditional physical store marketing model is bounded by gradually increasing store rental costs. There is the pressure within the industry to steadily reduce the number of physical stores by establishing a virtual platform. The integration of physical and virtual stores has become an irreplaceable advantage for many enterprises: it has led to a new store branding business model, the "Omni-channel Business Model," which emphasizes the integration of virtual and physical consumption, and completes the consumer experience process.

Also, it is reported that the overall online shopping frequency of consumers in daily shopping has approached that of physical shopping: approximately 4.5 out of 10 shopping experiences are completed through online shopping channels. The chain drugstore industry also believes that this development trend will affect the future development of its brand management. As a result, this issue is receiving a great deal of attention it's viewed as an important topic that can greatly improve brand loyalty and business performance.

Furthermore, according to a survey conducted by a famous Taiwanese consumer lifestyle consulting CompanyEastern Online in 2015, consumption patterns are slowly moving from offline to online. Moreover, online shopping will continue to grow in the future, and mobile online shopping is also expanding. As such, it is becoming more and more difficult to define consumption patterns, as consumer purchase decision behavior shifts from a linear process to "O-type consumption" that is, they are satisfied when buying products online and also visiting physical stores. Consequently, Zhan Hongzhi, the chairman of the aforementioned consulting company, has said: "This shows that manufacturers and platform operators should seamlessly intersect within every purchase event to make the process easy for consumers.

The evolution and transformation of retailing industry sectors usually require a long period of observation and research, and the chain drugstore industry is no exception. Issues requiring attention usually include brand positioning strategy, product development, and channel establishment and maintenance, among others.

\section{A. Research Questions}

The recent rapid changes in the global technology environment over the past few years have led to a decline in the performance of traditional physical channels, while the number of people visiting virtual channels has increased. Consequently, this paper focuses on best practices for integrating $\mathrm{O} 2 \mathrm{O}$ to formulate omni-channel retailing strategies and maximize profits. 
Specifically, this study focuses on the development of the
omni-channel retailing strategy of a case company and related issues, as well as whether the implementation of the omnichannel retail strategy affects the business performance of the case company. There are four major research issues summarized as follows:

- RQ1. Explore recent changes in consumer behavior trends within the drugstore industry, and how they affect omni-channel retailing strategy development.

- RQ2. Scrutinize how the case company implements omni-channel retailing strategies and the main reasons for implementing these strategies.

- RQ3. Investigate issues affecting the case company when they promote customer loyalty programs.

- RQ4. Examine the case company's overall business performance before and after implementing omnichannel retailing strategies.

\section{Theoretical framing}

\section{A. Channel Definition}

The American Marketing Association (AMA) defined a channel as "a group of organizations or individual groups that owns a product or facilitates the exchange of products during the marketing process where the product is transferred from the original owner to the end consumer." Kotler and Armstrong (2010) stated that a marketing channel refers to the process by which a specific good or service is transferred from a manufacturer to consumers or an individual or organization that acquires product ownership or assists in the transfer of ownership. Bowersox and Copper (1990) considered all corporate relationship systems involved in the transaction of products and services to be marketing channels that is, the communication media used by retailers and customers to interact, including physical stores, the Internet, and mobile devices (Goersch, 2002). Therefore, in this study, a channel is defined as the various intermediaries through which products or services are transferred from the producer to the end consumer, including distributor platforms.

\section{B. Physical Channels}

A physical channel refers to a retailer with a physical storefront. Peng and Dennis (2003) stated that physical access allows consumers to directly meet, communicate with, and make purchases from salespersons in specific places including department stores, supermarkets, mass merchants, grocery stores, convenience stores, and convenience stores. Consumers must physically visit these types of retail outlets to inquire about prices, collect product information, touch products, and make purchases. Peterson et al. (1997) believe that the physical channel has three functions: distribution, transaction, and communication. The distribution function involves consumers obtaining transaction goods directly in the store, which can meet their timeliness need, as they do not need to wait only if the product is in stock; moreover, their inventory and packaging can usually meet consumers' diverse purchasing needs. The transaction function mainly concerns ensuring that commodity transactions are convenient and riskfree. Finally, the communication function centers on the fact that consumers are used to viewing or touching products in person, and obtaining information directly from salespeople, to achieve the purpose of immediate delivery.

\section{Virtual Channels}

Bowersox and Cooper (1992) stated that non-store selling is selling products directly to consumers without using a retailing model. Kalakota and Whinston (1997) note that the virtual channel refers to the virtual transaction channel of the Internet, used to purchase, sell, or exchange products and services; use of this channel can reduce costs, help gather customer information, and increase service quality. Virtual channels have resulted in changes to traditional retail channels and reshaped consumers' shopping habits, especially due to direct contact with consumers. Scansaroli and Eng's (1997) research indicates that when consumers want to avoid traditional shopping due to the time required to travel and potential traffic problems, they will change their shopping habits and choose online shopping. Therefore, enterprises need to know how to best take advantage of virtual channels.

\section{$D$. Definition of $\mathrm{O} 2 \mathrm{O}$}

In recent years, e-commerce has developed rapidly. Faced with the prevailing trend of online sales, the operating cost of physical stores will increase in terms of staff salaries and store rents and thereby have a huge impact on the traditional retailing industry. Although some scholars originally believed that physical channels would be replaced by e-commerce, recent observations show that consumers tend to use the Internet to search for and compare products, and then visit the physical channel to purchase them. As such, consumers value both channels, and companies should simultaneously adopt various complementary marketing channel strategies to ensure both channels are attractive. However, enterprises also need to avoid conflicts associated with multi-channel or cross-channel integration.

"Virtual and physical integration" (also known as O2O: Online to Offline/ Offline to Online) is a business model that combines online and offline. Turban et al. (2009) classified e-commerce into three types: (a) traditional stores, or purely physical companies, (b) integrated virtual and physical organizations, and (c) e-commerce virtual organizations. Ogden et al. (2005) believed that in the future, the retail industry will rely on multi-channel traditional and virtual strategies, and integrate and develop interactive relationships with customers through these channels to provide products, information, and consumer service (Rangaswamy and Van Bruggen, 2005).

Furthermore, $\mathrm{O} 2 \mathrm{O}$ is widely discussed in the United States in association with the group-buying site Groupon (Luo 
Zhiying, 2012). In this case, O2O can be narrowly defined as: consumers go online to purchase goods and services from
physical stores, and then later visit the physical stores to complete the transactions. Moreover, as noted above, $\mathrm{O} 2 \mathrm{O}$ can also refer to offline to online, where online platforms are operated by manufacturers who also have physical stores; in this way, they can focus on being both a physical service provider or a virtual service provider (Luo Zhiying, 2012).

\section{E. Omni-channel Retailing Strategies}

In Europe and the United States, in addition to the above-mentioned $\mathrm{O} 2 \mathrm{O}$ classifications (computer networks and physical stores), consumers can also use other devices to get on the Internet, such as smartphones, tablets, notebooks, desktop computers, and even televisions. These cross-platform integrations can make the contact points between devices, goods, and consumers more convenient, especially for the multi-screen generation-being in line with $\mathrm{Z}$ generation some characteristics.

The retail market is changing from a multi-channel to an omni-channel model (Rigby, 2011). Omni-channel retailing is described by Beck and Rygl (2015) as follows: with the rise of mobile commerce, smartphones, tablets, and social networks have become key factors affecting sales, and consumers can cross-channel shop anytime and anywhere. Otype consumption and omni-channel retailing have resulted in firms striving to break through virtual and physical boundaries to integrate sales and service channels such as physical stores, websites, televisions, phones, mobile devices, and kiosks, among others, and thereby improve operational performance.

\section{F. Differences Between Omni-channel and Multi- Channel Retailing}

The biggest difference between omni-channel and multi-channel retailing is that in the former the gap between the channels becomes ambiguous, and the obstacles to be crossed, such as geographic location and consumer information acquisition, are relatively small (Verhoef et al., 2015). Although multi-channel retailing focuses on the interaction between the channels, omni-channel retailing goes beyond this by also focusing on the community and access to mass/social media (Verhoef et al., 2015). For example, there are now many shops that promote card punching on Facebook for discounts. Furthermore, connecting with consumers through omni-channel retailing can be achieved through the use of apps, i-Beacon, mobile positioning, and other methods. Consumers can "showroom", where they first experience products in a physical store and then go online to buy them; they can also "webrooming", where they obtain discounts online that they use in physical stores. From a consumer perspective, omni-channel retailing provides additional channels to better understand products and shopping in general. On the other hand, from a retailer perspective, omnichannel retailing allows for the integration of various channels, and can instantly glean consumer opinions about goods and services.

Current research on multi-channel retailing is mainly driven by the rapid development of online sales and intrinsically changing consumer behaviors (Kozlenkova et al.,2015). Retailers initially developed multi-channel systems to meet the additional challenges associated with the advent of successful e-commerce. Several authors have argued that the retailing industry is moving towards omni-channel retailing, where the distinction between offline and online channels is lost (Beck and Rygl, 2015; Verhoef et al., 2015). In fact, with an advanced omni-channel approach, neither the customer nor the retailer can distinguish between channels anymore (Brynjolfsson et al., 2009; Gallino \& Moreno, 2014; Verhoef et al., 2015; Bell et al., 2018). Omni-channel focused on a truly integrated approach across the whole retail operation to deliver a seamless response to the consumer experience through all available shopping channels including mobile internet devices, computers, televisions, in-store, or catalogs (Saghiri et al., 2017), whereas multi-channel focuses on customer transactions with the business (browse, buy, returns) through independently managed channels, including retail stores, online stores, and mobile apps, among others.

\section{G. Business Performance}

Stern, El-Ansary, and Coughlan (1996) stated that channel performance includes financial performance and the contribution of channel members, and use cost and revenue as the basis for channel allocation. Generally speaking, the indicators often used to measure business performance can be divided into financial performance and non-financial performance. The main measurement aspects in terms of financial performance are: sales revenue or net sales, return on assets, and net income rate before tax, among others. On the other hand, non-financial performance includes organizational stability, employee turnover, employee performance, and employee satisfaction (Kirchoff, 1977). However, Reichheld and Sasser (1990) found that for the retail service industry, each 5\% increase in customer retention rate can increase the profit rate by $25-125 \%$. Omni-channel marketing cannot be considered as a serious advancement if it does not demonstrate a positive impact on performance measures deemed critical by sales scholars (Rodriguez and Trainor, 2016). The management literature has shown that an organizational transformation to omni-channel retailing has a positive effect on firm sales growth (Cao and Li, 2015; Wollenburg et al., 2016). Based on the above, this study selected two types of financial performance and non-financial performance as the main measurement indicators of business performance.

\section{$H$. Introduction to the Drugstore Industry in Taiwan 1) Drugstore Definition}

The top management of the leading drugstore brand in Taiwan defined drugstores as follows: Stores with a higher 


\section{(C) Center for Promoting Education and Research (CPER) USA}

www.cpernet.org

ratio of medical items are called pharmacies, while those with a higher ratio of make-up items are called beauty makeup stores. However, in Japan, some stores such as Matsumoto Kiyoshi carry a balanced proportion of medicine and makeup items, and these are what we call drugstores. As such, drugstores operate with health and beauty as the main business - all product categories are seen as equivalent, and this extends to cosmeceutical-related products (a combination of cosmetics and pharmaceuticals) and daily necessities. There is a pharmacist and drug consulting service in the store. However, the items in the drugstore are arranged in an openshelf style.

2)The Difference Between Drugstores and Pharmacies

The operation methods of modern drugstores and traditional pharmacies are different. Unlike drugstores, where almost all products are displayed openly on shelves, traditional pharmacy products are behind a counter, and a pharmacist provides consulting services. Customers decide which products to buy only after asking the pharmacist about the pharmacological function and price. As a result, the pharmacist has an important role with respect to facilitating customer purchases, and customers cannot make price comparisons until they have left the store.

\section{Methodology}

\section{A. Case Study Method}

Case studies can include one or more cases with different levels of analysis (Yin, 1984). Eisenhardt (1989) argued that case studies focus on research strategies regarding various changes that occur in a single environment-this method usually also incorporates multiple data collection methods, such as archives, interviews, questionnaires, and field observations. According to Bonoma (1985), case studies have the following seven important features: the research environment is non-manipulated; there can be one or more research objects (such as companies, groups, or individuals); they require an in-depth understanding of the complexity of each research object; they are more suitable for use when a problem is still in the exploratory stage, and there are not many previous studies to follow; the research does not call for variable manipulation; the research does not focus on current issues; and they are more useful for researching the why and how about research questions, which can be used to track the basis of future related research variables.

More specifically, in terms of the aforementioned four research questions regarding why and how characteristics, indepth interviews with top drugstore executives were conducted to better understand extant issues/strategies.

Based on the above, a case study method was deemed appropriate to investigate changes in the market and the "why" behind developing an omni-channel retailing strategy. Through an investigation and analysis of case B companies, we can better comprehend integration issues regarding incorporating virtual and physical stores into an omni-channel retailing strategy.

\section{B. In-depth Interviews and Research Setting}

The four interviewees in this study were senior executives (top-level, marketing, physical channel, and virtual channel) who participated in the omni-channel innovation process of B company. The respondents' average number of years of work experience exceeded 15 years. Semi-structured interviews were chosen to match the study objectives: a semistructured questionnaire was designed based on the relevant literature to conduct these interviews.

The interview period was from October to December in 2019, and the average time required for each interview was about 1.5 hours. Interviews focused on issues such as changes in business performance before and after the implementation of the omni-channel retailing strategy, and related issues that the interviewees considered important. When points made during the interview were unclear, the interviewee was consulted by telephone or e-mail to provide clarification.

After the interviews, the content was analyzed; later, secondary data was collected about the case company, and a case analysis was conducted through different data sources.

\section{Research Design}

This study designed interview questionnaires based on the literature and case-related secondary data. These issues are as follows:

$\cdot R Q 1$. Explore recent changes in consumer behavior trends within the drugstore industry, and how they affect omni-channel retailing strategy development.

-RQ2. Scrutinize how the case company implements omni-channel retailing strategies and the main reasons for implementing these strategies.

RQ3. Investigate issues affecting the case company when they promote customer loyalty programs.

$\cdot \boldsymbol{R Q 4 . E x a m i n e ~ t h e ~ c a s e ~ c o m p a n y ' s ~ o v e r a l l ~ b u s i n e s s ~}$ performance before and after implementing omnichannel retailing strategies.

\section{Findings}

- RQ1. Explore recent changes in consumer behavior trends within the drugstore industry, and how they affect omnichannel retailing strategy development?

The senior executives said that changes in consumer behavior will affect omni-channel retailing development.

They said they paid more attention to (a) what changes occur in terms of consumer behavior, and (b) how they should respond following the change to omni-channel retailing. In short, they expected to grow and thrive together with their customers. The main reasons were to better serve the young Internet generation and do something to revitalize the brand image.

Furthermore, several years' worth of internal data analysis includes information on how close consumers are to the 


\section{(C) Center for Promoting Education and Research (CPER) USA}

www.cpernet.org

shelves when they the store, or how often they pick up goods and then put them down. These behaviors can be recorded, filtered, and analyzed; they represent important sources of marketing data that can allow us to pursue business opportunities. These phenomena can fully be interpreted by Peng and Dennis's (2003) statement-salesperson/personal selling, intrinsic changing of consumer behavior (Kozlenkova et al., 2015), and real experience in physical stores like "showrooming".

- RQ2. Scrutinize how the case company implements omni-channel retailing strategies and the main reasons for implementing these strategies?

Concerning responding to customers' diverse needs, in recent years they profited by analyzing existing customer data and activating store-type remodeling plans in physical stores.

One executive said: "It was not that we decided which store types we wanted; instead, we based store environment decisions on customer needs and then decided what services to provide." To accomplish this, they analyzed accumulated data, extrapolated product attractiveness figures based on cross-store consumption statistical data, and further designed a niche store-type.

They also observed the sales trends for their product lines, including replenishment needs for best-selling products or adjustments for slow-moving goods, to grasp opportunities or predict crises in advance.

In the new retailing environment, offline stores will not be replaced by online stores. Our interviewees said they must withstand the pressure associated with online shops' growth, and utilize their data science advantages and strategies as follows: "Our business models have continued to innovate, and new technology applications have adjusted the retailing business model, including online and offline integration, due to mobile devices becoming consumer touchpoints".

Omni-channel retailing emphasizes the shopping experience and has become synonymous with the new retail era. In terms of this trend, the company opened Asia's first "digital beauty experience store" in 2016. This three-floor store includes more than 50 digital interactive devices that result in an extraordinary consumer shopping experience with new digital technology. Moreover, payment methods have become diverse: they have gradually accepted new mobile payment services such as Apple Pay, Samsung Pay, Android Pay, and LINE Pay.

Their latest-generation brand concept store, tech-fun, opened in April 2018. This concept store has also added more technological elements, such as a virtual makeup machine, point-to-order virtual shelves, makeup test stations, and selfcheckout machines. Shortly, there will be other major digital transformational strategies, such as the launch of an updated version of App 2.0, and their own "Pay" app. At present, their member app has been downloaded over 2 million times.
The senior executives repeatedly emphasized that ecommerce has been key in maintaining their growth momentum over the past few years, and also noted that only ecommerce had grown, while the overall store revenue fell. This omni-channel retailing strategy is not $\mathrm{O} 2 \mathrm{O}$ we called it "O+O", referring to the fact that even when e-commerce performance grows, boosting the sales performance of physical stores and the overall performance together remains important. Moreover, while the e-commerce team is seen as the lead concerning e-commerce performance, other teams such as marketing and IT have roles to play. Everyone in the firm has to include e-commerce in their performance evaluation.

For example, about $20 \%$ of customer's order through the online store and choose to pick up the goods at physical stores. Store staff can act as facilitators for on-site purchases during these pick-ups, creating an opportunity for additional sales. At present, approximately $50 \%$ of customers in this situation make additional purchases when they pick up products ordered online. Conversely, those who make offline purchases often receive online discount coupons. The executives believe that offline and online channels work together to increase performance.

In sum, the main point of the omni-channel strategy is that each channel does not operate independently, but actively shares information with other channels. By reducing the distance between service providers and consumers through online and offline data integration, consumers can interact with and purchase from firms even faster than before. These statements match the definition of omni-channel retailing (Beck and Rygl, 2015), meaning that $\mathrm{O}+\mathrm{O}$ can be regarded as a type of omni-channel retailing.

- RQ3. Investigate issues affecting the case company when they promote customer loyalty programs.

- RQ4. Examine the case company's overall business performance before and after

implementing omni-channel retailing strategies.

This firm launched their membership card in 2008. Presently, there are almost 6 million members, which equates to almost a quarter of the total population of Taiwan. Members benefits include: (a) one dollar spent earns one point, and 300 points can be used to deduct one dollar from the cost of purchase (bonus points accumulated in one year expire on $11 / 30$ of the following year); (b) every Saturday, one point is worth six points; (c) exclusive counter discounts, and (d) member-only special offers through online stores.

For online and mobile shopping, they utilize various favorable prices or promotional activities that differ from those used in the offline stores-for example: offline stores offer to buy one get one free, but online channels offer one for half price. This method can increase the motivation for consumers to shop online. Online shoppers can choose to pick up purchases at offline stores. At present, the online purchase of 
people who pick up and rate of adding buying in offline stores is close to $50 \%$. When shopping at physical stores, they will also give online stores discount coupons form a good shopping cycle, allowing online and offline circulation.

In an attempt to deepen relationships with loyal members, they initiated a global "VIP Honorary Membership Program" in 2018 utilizing data technology to enhance connections and interactions with customers. This included a "VIP Points Member" system for members who spent at least $\$ 20,000$ NT annually in Taiwan; members can be promoted to VIP points members on the 1 st of every month and enjoy several additional promotions, such as exclusive events, gold price, and many other benefits to effectively improve the stickiness of the brand channel. At present, there are nearly 100,000 VIP gold members.

In a recent internal survey, customers noted that they pay attention to their relationship with various retailers; they noted that providing high-quality products, great prices, and considerate service is not enough to maintain a close connection with customers. Furthermore, in the global market, about two-thirds of all customers are eligible for VIP membership and become VIP members the following year. Each year, these VIP members consume eight times more than ordinary members; moreover, newly upgraded VIP members' annual consumption doubles.

On the other hand, our strategic focus on the membership economy. Until now, we have launched a membership card over 11 years, which currently has over 5.2 million members. On average, one in every 3 to 4 people in Taiwan is a member. Shortly, they plan to utilize three strategies in addition to the focus on memberships: introduce new image ambassadors, enhance the member experience, and integrate offline and online channels. As noted above, as new technology consumption habits mature, they plan to launch their mobile payment system in Taiwan.

Enabling the new endorser will help increase brand visibility. Next, they plan to strengthen the recruitment of Gen $\mathrm{Z}$ members through multiple campus tours. They have also strengthened the membership experience by offering free movie coupons, travel coupons, and music parties. Also, they activated an official LINE account to provide consumers preferential information, and a way to check their accumulated points. Once developed, their app will add new functions including using maps to locate products and applying for online membership cards.

The company currently has over 560 physical stores in Taiwan, and it ranks among the leading domestic drugstore firms. Over the last years, sales revenues increased by nearly $10 \%$, mainly due to the strengthening of member operations. Also, member point redemption activities increased the average number of visitors by more than $10 \%$. It is estimated that they will have over 620 physical stores by the end of 2020.

\section{Discussion}

\section{A. Theoretical Contributions}

Prior studies investigated $\mathrm{O} 2 \mathrm{O}$ or the omni-channel concept have mostly focused on online and offline integration (i.e. increasing online with decreasing offline or vice versa). The current study notes that the new concept " $\mathrm{O}+\mathrm{O}$ " can result in boosted performance and a win-win concerning offline and online channels.

Questions remain, such as whether offering discount coupons through virtual platforms (such as apps) can be used to divert online customers to physical channels, and whether physical store salespeople can also use the app as a marketing tool to encourage consumers to browse and order goods online. According to the research findings, B company can use its app to send push notifications. When consumers use the app or social media software such as LINE to shop, B company can also gather product pick-up data for each store to help formulate strategies going forward.

\section{B. Managerial Implications}

This paper explores omni-channel retailing strategies within the Taiwan drugstore industry, specifically about B company. In-depth interviews about four main issues were conducted with senior executives to better understand how B company integrates physical and virtual channels to meet consumers' needs and improve performance. Furthermore, as omni-channel retailing moves forward and consumer behaviors change, $\mathrm{B}$ company must be innovative and proactive to ensure continued success examples including introducing and upgrading their membership card, offering member perks through their app, and increasing accepted payment types, especially concerning mobile users. B company must also continuously strive to drive online consumption based on the advantages associated with offline channels.

Concerning overall e-commerce or mobile commerce development, online shopping will continue to grow in the future. A complementary omni-channel retailing model that combines physical services with the convenience of online shopping will be beneficial. B company stores are already all over Taiwan, which is advantageous to their omni-channel strategy: they can increase the number of members through app management and develop a differentiated and diversified modification system. As the mobile payment penetration rate increases, membership numbers should grow.

Implementing an omni-channel retailing strategy will generate new opportunities, improve employees' productivity, increase sales revenue, and bring new consumers into the fold. Moreover, these strategies can increase overall brand awareness and return on investment (ROI). 


\section{CCenter for Promoting Education and Research (CPER) USA}

WWW.cpernet.org

\section{Limitations and Future Research Directions}

Two findings are evident: there is an increased threat from competing new brands (e.g. Poya) in Taiwan, and while online stores are increasing, offline stores still exist (especially in the retail service industry). E-commerce cannot completely replace the ability to experience goods and services in a physical store. As such, determining how to increase B company's proportion of consumers is worth further exploration.

Secondly, the future of retailing must integrate new technology: logistics, business flows, cash flows and information flows need to be consolidated. This is commonly referred to as smart retailing. B company consumers utilize mobile payment at a higher rate than the average for general retailers or competitors; however, this rate is still low compared to their foreign parent company. Future researchers can explore how to increase the proportion of consumers who use mobile payment methods.

Finally, the largest study limitation is the difficulty associated with obtaining actual data on business operations, as firms want to maintain confidentiality. While estimates can be made based on secondary data from the foreign parent group's consolidated statements or business magazines, this is insufficient. A discussion of the effects on operations after implementing an omni-channel retailing strategy (i.e. whether other factors also affect performance directly) would be worthwhile.

\section{References}

Beck, N., \& Rygl, D. (2015). Categorization of multiple channel retailing in multi-, cross-, and omni-channel retailing for retailers and retailing. Journal of Retailing and Consumer Services, 27, 170-178.

Bell, D. R., Gallino, S., \& Moreno, A. (2014). How to win in an omni-channel world. MIT Sloan Management Review, $56(1), 45$.

Bell, D. R., Gallino, S., \& Moreno, A. (2018). Offline showrooms in omnichannel retail: Demand and operational benefits. Management Science, 64(4), 1629-1651.

Bonoma, T. V. (1985). Case research in marketing: Opportunities, problems, and a process. Journal of Marketing Research, 22(2), 199-208.

Bowersox, D. J., \& Copper, M. B. (1990). Strategic marketing channel management (pp. 4, 338-361). New York: McGrawHill.

Brynjolfsson, E., Hu, Y. J., \& Rahman, M. S. (2009). Battle of the retail channels: How product selection and geography drive cross-channel competition. Management Science, 55(11), 1755-1765.

Brynjolfsson, E., Hu, Y. J., \& Rahman, M. S. (2013). Competing in the age of omni-channel retailing. MIT Sloan Management Review, 54(4), 23-29.

Bucklin, L. P. (1966). A theory of distribution channel structure. University of California: Institute of Business and Economic Research.

Butler, P., \& Peppard, J. (1998). Consumer purchasing on the Internet: Processes and prospects. European Management Journal, 16(5), 600-610.

Cao, L. \& Li, L. (2015). The impact of cross-channel integration on retailers' sales growth. Journal of Retailing, 91(2), 198-216.

Cao, L., \& Li, L. (2018). Determinants of retailers cross-channel integration: An innovation diffusion perspective on omnichannel retailing. Journal of Interactive Marketing, 44, 1-16.

Chan, P. S., \& Pollard, D. (2003). Succeeding in the dotcom economy: Challenges for brick \& mortar companies. International Journal of Management, 20(1), 11-16.

Eisenhardt, K. M., \& Schoonhoven, C. B. (1989). Resource-based view of strategic alliance formation: Strategic and social effects in entrepreneurial firms. Organization Science, 7(2), 136-150.

Gallino, S., \& Moreno, A. (2014). Integration of online and offline channels in retail: The impact of sharing reliable inventory availability information. Management Science 60(6), 1434-1451.

Goersch, D. (2002). Multi-channel integration and its implications for retail web sites. ECIS 2002 Proceedings, 11(4), 748-758.

Kalakota, R. \& Whinston, A. B. (1997). Electronic commerce: A manager's guide. Addison-Wesley.

Kim, J., \& Park, J. (2005). A consumer shopping channel extension model: Attitude shift toward the online store. Journal of Fashion Marketing and Management, 9(1), 106-120. 
Kirchoff, B. A. (1977). Organisational effectiveness and policy. Academy of Management Review, 2(3), 347-355.

Kotler, P., \& Armstrong, G. (2010). Principles of marketing. Pearson education.

Kotler, P., Kartajaya, H., \& Setiawan, I. (2016). Marketing 4.0: Moving from traditional to digital. John Wiley \& Sons.

Kozlenkova, I. V., Hult, G. T. M., Lund, D. J., Mena, J. A., \& Kekec, P. (2015). The role of marketing channels in supply chain management. Journal of Retailing, 91(4), 586-609.

O'Cass, A., \& Fenech, T., (2003). Web retailing adoption: Exploring the future of internet users' web retailing behavior. Journal of Retailing and Consumer Services, 10(2), 81-94.

Ogden, J. R., \& Ogden, D. T. (2005). Retailing: Integrated retail management. Boston: Houghton Mifflin Company.

Peterson, R. A., Sridhar B., \& Bart J. B. (1997). Exploring the implications of the internet for consumer marketing. Journal of the Academy of Marketing Science, 25(4), 329-346.

Rangaswamy, A., \& Van Bruggen, G. H. (2005). Opportunities and challenges in multichannel marketing: An introduction to the special issue. Journal of Interactive Marketing, 19(2), 5-11.

Reichheld, F. F., \& W. E. Sasser, Jr. (1990). Zero defections: Quality comes to services. Harvard Business Review, 68(5), 105111.

Rigby, D. (2011). The future of shopping. Harvard Business Review, 89(12), 65-76.

Rodriguez, M., \& Trainor, K. (2016). A conceptual model of the drivers and outcomes of mobile CRM application adoption. Journal of Research in Interactive Marketing, 10 (1), 67-84.

Saghiri, S., Wilding, R., Mena, C., \& Bourlakis, M. (2017). Toward a three-dimensional framework for omni-channel. Journal of Business Research, 77, 53-67.

Scansaroli, J. A., \& Eng, V. (1997). Consumers online. Chain Store Age, 73(1), 5A-8A.

Stern, L. W., El-Ansary, A. I., \& Coughlan, A. T. (1996). Marketing channels. Prentice-Hall: Upper Saddle River, NJ.

Turban, E., Lee, J. K., King, D., Liang, T. P., \& Turban, D. (2009). Electronic commerce 2010. Prentice Hall Press.

Verhoef, P. C., Kannan, P. K., \& Inman, J. J. (2015). From multi-channel retailing to omni-channel retailing: Introduction to the special issue on multi-channel retailing. Journal of Retailing, 91(2), 174-181.

Wollenburg, J., Holzapfel, A., \& Hübner, A. (2019). Omni-channel customer management processes in retail: An exploratory study on fulfillment-related options. Logistics Research, 12(7).

Wollenburg, J., Holzapfel, A., Hübner, A., \& Kuhn, H. (2016). Configuring retail fulfillment processes for omni-channel customer steering. International Journal of Electronic Commerce 22(4), 540-575.

Yin, R. (1984). Case study research: design and methods (1st ed.). Beverly Hills, CA: Sage Publishing. 